\title{
OFFICERS PAST AND PRESENT
}

\section{PRESIDENT}

J. H. Van Amringe, 1888-1890, Eliakim H. Moore, 1900-1902, Emory McClintock, 1890-1894, Thomas S. Fiske, 1902-1904, G. W. HILL, 1894-1896, W. F. OsGood, 1904-1906, Simon NewCOMB, 1896-1898, H. S. WhITE, 1906-1908, R. S. WoodWARD, 1898-1900, MAXIME Bôcher, 1908-1910,

H. B. FiNe, 1910-

\section{VICE-PRESIDENTS}

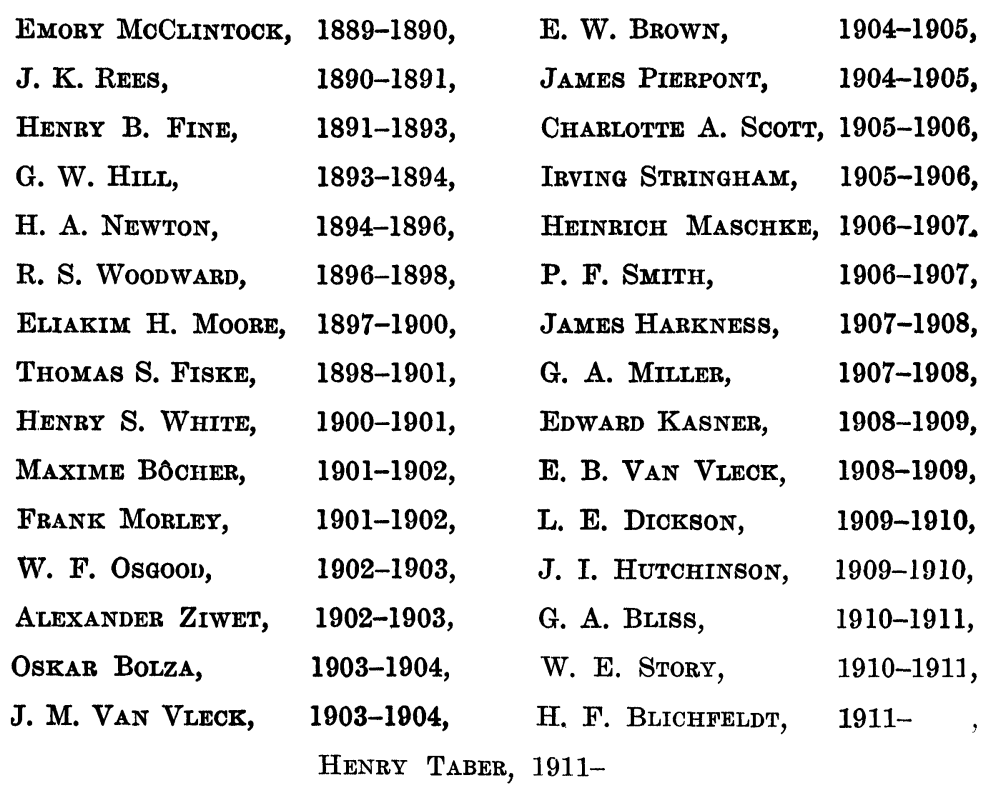




\title{
OFFICERS PAST AND PRESENT
}

\author{
SECRETARY
}

\begin{tabular}{llll} 
Thomas S. FISKE, & $1888-1895$, & F. N. COLE, & $1895-$ \\
\multicolumn{4}{c}{ TREASURER } \\
I'HOMAS S. FISKE, & $1888-1891$, & HAROLD JACOBY, & $1896-1899$, \\
HAROLD JACOBY, & $1891-1894$, & W. S. DeNNETT, & $1899-1907$, \\
R. S. WoOdWARD, & $1894-1896$, & J. H. TANNER, & $1907-$
\end{tabular}

\section{LIBRARIAN}

D. A. Murray, 1892-1893, Edward L. Stabler, 1894-1895, Gustave Legras, 1893-1894, Pomeroy Ladue, 1895-1901, D. E. SMITH, 1901-

\section{COMMITTEE OF PUBLICATION}

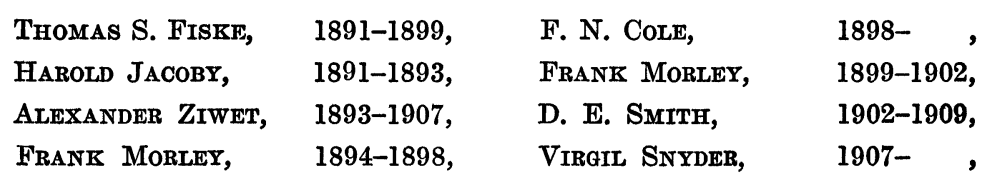
E. W. Brown, 1909-

EDITORIAL COMMITTEE OF THE TRANSACTIONS

Eliakim H. MOORE, 1899-1907, H. S. WhITE, 1906- , E. W. Brown, 1899-1906, MAXIME Bôcher, 1907-1909, T. S. FISKE, 1899-1905, W. F. OsGood, 1909-1910, E. B. VAN VleCK, 1905-1910, L. E. Dickson, 1910- , MAXIME BÔCHER, 1910- . 